PDFlib PLOP: PDF Linearization, Optimization, Protection

Page inserted by evaluation version www.pdflib.com - sales@pdflib.com 


\title{
Regulation of Glucocorticoid Receptor Function through Assembly of a Receptor-Heat Shock Protein Complex ${ }^{a}$
}

\author{
KEVIN A. HUTCHISON, ${ }^{b}$ LAWRENCE C. SCHERRER, ${ }^{b}$ \\ MICHAEL J. CZAR, ${ }^{b}$ LOUIS F. STANCATO, $b$ \\ YU-HUA CHOW, ${ }^{c}$ RICHARD JOVE, $c$ \\ AND WILLIAM B. PRATT ${ }^{b, d}$ \\ Departments of ${ }^{b}$ Pharmacology and \\ cMicrobiology and Immunology \\ The University of Michigan Medical School \\ Ann Arbor, Michigan 48109
}

It is now well established that steroid receptors in hormone-free cells are associated with the $90-\mathrm{kDa}$ heat shock protein, hsp90 (for review, see Pratt ${ }^{1,2}$ ). The receptorheat shock protein interaction has been most extensively studied for glucocorticoid receptors (GR) and progesterone receptors (PR). In both cases it has been shown that hsp90 interacts with the hormone binding domain (HBD), ${ }^{3-6}$ and that binding of steroid to the HBD promotes dissociation of the receptor from hsp $90 .^{2}$ From the study of mutant receptors it is clear that the HBD performs at least three functions required for hormonal regulation of receptor function: (1) It represses the transcriptional activating activity of the receptor, (2) it binds hormone, and (3) it determines hormone-regulated derepression of receptor function. ${ }^{7,8}$ The inactivating function of the HBD can be conferred to fusion proteins, bringing their activity under hormonal control., ${ }^{9,10}$ Recently we have used some fusion proteins containing $\beta$-galactosidase and portions of the rat $\mathrm{GR}^{11}$ to demonstrate that the GR HBD is sufficient to confer hormonally regulated binding of fusion protein to hsp90.12 Taken together with earlier reports demonstrating a correlation between hormone-regulated transcriptional activation and hsp 90 binding by mutant GRs, 3,5 these observations support the notion that hsp90 may be responsible for the general inactivation function of the HBD.

In the past three years, it has become clear that the heterocomplex form of steroid receptors contains other proteins in addition to hsp90, including two other heat shock proteins, hsp70 and hsp56. ${ }^{13-17}$ Coimmunoadsorption studies with monoclonal antibodies against hsp56 and hsp90 have shown that a heterocomplex containing these three heat shock proteins exists in cytosols independent of the presence of steroid receptors. ${ }^{18,19} \mathrm{Hsp} 70$ is a polypeptide-binding protein that appears to have a protein folding/unfolding activity and is thought to play a role in protein trafficking in the to R.J.

${ }^{a}$ This work was supported by NIH grants DK31573 and CA28010 to W.B.P., and CA47809

${ }^{d}$ Address correspondence to Dr. William B. Pratt, Department of Pharmacology, 6448 Medical Science Bldg. I, The University of Michigan Medical School, Ann Arbor, Michigan 48109-0626. 
cell..$^{20}$ Hsp56 is an immunophilin of the FK506 binding type..$^{21,22}$ Other immunophilins display peptidyl-prolyl isomerase activity, ${ }^{23}$ and hsp56 has sequence homology with peptidyl-prolyl isomerase. ${ }^{24}$ The immunophilins are also thought to play a major role in protein folding and trafficking in the cell. ${ }^{23}$ It has been proposed that the receptor heterocomplex may represent steroid receptor that is recovered in cytosols still bound to components of a protein trafficking system. ${ }^{25}$ One possibility is that receptors remain attached to this system while they shuttle through the cytoplasm and into the nucleus. Thus, in such a model, in the absence of hormone they remain docked to this complex, and when they are exposed to hormone, they dissociate from the hsp90 component and progress from the protein trafficking system to the sites where transcriptional activation occurs. ${ }^{25}$ Consistent with such a model, we have found that more primitive members of the steroid/thyroid hormone receptor family, such as retinoic acid or thyroid hormone receptors, do not bind in a stable manner to hsp $90,{ }^{26,27}$ and in the hormone-free cell, these receptors proceed directly to high-affinity nuclear binding sites without docking. ${ }^{2}$

Cytosolic receptors that are bound to the heat shock protein complex are functionally different from dissociated receptors. The major difference common to all of the steroid receptors and the dioxin receptor is that receptor in the heterocomplex does not bind to DNA, whereas the dissociated receptor has DNA-binding activity. ${ }^{2}$ Another functional difference is that some of the receptors must be bound to hsp90 for the HBD to be in an appropriate conformation for high-affinity ligand binding activity. The hsp90 requirement for steroid binding has been shown for the $\mathrm{GR}^{28}$ and for the dioxin receptor, ${ }^{29}$ but the sex steroid receptors apparently have similar steroid binding affinities in their heterocomplex and dissociated forms. Although the GR must be bound to hsp90 to have a competent steroid binding site, the liganded receptor can be dissociated from hsp90 without loss of prebound steroid.

One major impediment to studying how steroid receptor binding to the heat shock protein complex directly affects receptor function has been an inability to reform the complex from dissociated constituents in a cell-free system. It is quite clear that the binding of hsp90 to the receptors does not reflect a simple thermodynamic equilibrium. Rather it seems likely that the receptor undergoes a conformational change on dissociation from hsp90 that eliminates the hsp90 binding site on the surface of the HBD. Because efforts to rebind hsp90 to receptors in vitro were unsuccessful, we asked whether receptor translated in vitro was bound to hsp90. Denis and Gustafsson $^{30}$ demonstrated that rat GR translated in rabbit reticulocyte lysate behaved as the 9S heterocomplex. The newly translated receptor did not bind to DNA but it was converted to the 4S, DNA-binding form by binding it with dexamethasone and heating. These observations strongly suggest that the rat GR had combined with hsp90 in the lysate to produce a hybrid rat GR-rabbit hsp90 complex that functioned like the native GR heterocomplex isolated from the cell.

Our laboratory developed a direct assay for detecting association of hsp90 with in vitro translated GR. ${ }^{31}$ We translated rat GR both in rabbit reticulocyte lysate, which contains $\sim 2 \mu \mathrm{M}$ hsp90, and in wheat germ extract, which does not contain protein reacting with anti-hsp 90 antibodies of broad spectrum reactivity within the animal kingdom. We found that GR translated in reticulocyte lysate was bound to rabbit hsp90, that it bound steroid with high affinity, and that it was in a non-DNAbinding form that could be transformed to the DNA-binding state. Schlatter et al. ${ }^{32}$ demonstrated that the HBD is sufficient for forming a complex with hsp90 in this system. In contrast to the rabbit lysate, GR translated in the plant extract was not bound to a plant protein; it had no steroid binding activity (despite translation of the full-length receptor); and it was translated in the DNA-binding form..$^{26,31}$ 
At this time, we thought that binding of hsp 90 might be obligatorily coupled to GR translation and more specifically with translation termination. ${ }^{31}$ Smith et al. ${ }^{33} \mathrm{de}-$ monstrated this is not the case when they incubated immunoadsorbed, hormone-free chicken PR with rabbit reticulocyte lysate and demonstrated binding of rabbit hsp 90 and hsp70 to the avian receptor. This was a critical observation because it allowed us to ask whether reconstitution of the GR heterocomplex was accompanied by reactivation of steroid binding capacity and inactivation of DNA-binding activity. If these functional changes occurred on reforming the GR-hsp90 complex, the reticulocyte lysate might prove to be a very important system for dissecting the mechanisms by which changes in the folding state of the receptor occur and how the folding state of the receptor may affect its function. These studies are reviewed briefly herein.

\section{MATERIALS AND METHODS}

The rat fibroblast 3Y1 cell line expressing the temperature-sensitive PA104 pp60 ${ }^{\text {-src }}$ mutant ${ }^{34}$ was generated by transfection of expression vectors containing the molecularly cloned src sequence (B. Brott and R. Jove, unpublished data). The BuGR monoclonal antibody prepared against the rat $\mathrm{GR}^{35}$ was kindly provided by Dr. Robert Harrison (University of Arkansas for Medical Science), and rabbit serum against hsp70 and hsp90 36 was a generous gift from Dr. Ettore Appella (National Cancer Institute). Anti-pp60 ${ }^{\text {src }}$ N2-17 monoclonal antibody (directed against aminoterminal residues $2-17$ of pp60 $0^{s r c}$ ) and synthetic pp60src N2-17 peptide were from Microbiological Associates (Bethesda, MD). Anti-Raf rabbit antiserum was prepared against a peptide corresponding to the carboxy-terminal 12 amino acids of human c-Raf-1 (Y.-H. Chow, D. Retallack and R. Jove, unpublished). The IgM monoclonal antibody against p50 was provided by Dr. Gary Perdew (Purdue University). ${ }^{37}$

L929 mouse fibroblasts (L cells) and rat 3Y1 cells stably transfected with PA104 pp60 $0^{\nu-s r c}$ were cultured as described previously. ${ }^{38,39} \mathrm{~A}$ recombinant baculovirus containing the complete coding sequence of human c-Raf-1 cDNA was constructed (Y.-H. Chow and R. Jove, unpublished) and used to infect Sf9 insect cells as described..$^{40}$ Cytosol was prepared from $L$ cells in $10 \mathrm{mM}$ HEPES buffer and from 3 Y1 and Sf9 cells in RIPA buffer as described previously. 38,39

Aliquots of cytosol (usually $400 \mu \mathrm{L}$ of $\mathrm{L}$ cell cytosol or $0.7-1.0 \mathrm{~mL}$ of $3 \mathrm{Y} 1$ or Sf9 cytosol) were immunoadsorbed to protein A-Sepharose with appropriate immune or nonimmune antibody, and the immunoadsorbed pellets were washed by suspension and centrifugation in buffer. Prior to incubation with reticulocyte lysate, immunoadsorbed receptors or pp60src were stripped of associated hsp 90 by incubation with $0.5 \mathrm{M} \mathrm{NaCl}$ followed by three washes with salt-free buffer as described. ${ }^{38,39}$ For reconstitution of heterocomplexes, immune pellets stripped of hsp90 were mixed with $50-100 \mu \mathrm{L}$ of rabbit reticulocyte lysate with additions as noted in figure legends; the mixture was suspended by trituration and incubated for $20 \mathrm{~min}$ at $30^{\circ} \mathrm{C}$. Following the incubation, the pellets were washed four times with a buffer containing $20 \mathrm{mM}$ molybdate to stabilize the heterocomplex.

In some experiments a portion of the immunoadsorbed GR was aliquoted for assay of steroid binding. The remainder of the immunopellet, or the entire immunopellet in the case of pp60 $0^{\nu-s r c}$ and c-Raf-1, was extracted with $200 \mu \mathrm{L}$ SDS sample buffer, and proteins were resolved on $7 \%$ SDS-polyacrylamide gels. Proteins were transferred to Immobilion $P$ membranes, incubated with the appropriate primary antibody to detect GR, pp60 ${ }^{\text {rssc }}$, c-Raf-1, hsp90 or hsp70 and then incubated a second time with the appropriate ${ }^{125}$ I-labeled anti-mouse or anti-rabbit IgG as described. ${ }^{38,39}$ 


\section{RESULTS}

\section{Association of Glucocorticoid Receptor with hsp90 Regulates Receptor Activity}

The general method used for reconstituting the GR heterocomplex is illustrated in the experiment of FIGURE 1. Lane 1 presents the immunoadsorbed GR stripped of associated proteins, (note the absence of hsp90). As shown in the autoradiogram in the bottom panel, this hsp90-free receptor does not bind the site-specific affinity label $\left[{ }^{3} \mathrm{H}\right]$ dexamethasane 21 -mesylate. Lane 3 shows an identical sample after incubation with reticulocyte lysate. Hsp90 is now associated with the receptor and the receptor binds steroid. Several observations suggest that generation of steroid binding activity is due to reassociation of the GR with hsp90. For example, generation of steroid binding activity is blocked by peptides that block association of hsp $90,{ }^{4}$ and there is a direct relationship between the amount of hsp90 bound to immunopurified GR and the number of specific binding sites that are generated. ${ }^{41}$

When they first reconstituted the chicken PR heterocomplex with reticulocyte lysate, Smith et al. ${ }^{33}$ found that the hormone-free receptor was reconstituted with hsp90 and hsp70, but the progesterone-bound receptor was not. This is potentially a very important observation because it is consistent with the in vivo effect of steroid in promoting hsp 90 dissociation. FIGURE 2 shows a similar result with the GR. In this experiment, steroid-bound or hormone-free GR was immunoadsorbed from L cell cytosol, stripped of associated proteins (lane 3 ), and incubated with reticulocyte lysate. The hormone-free GR is reassociated with hsp90 (lane 5) to nearly the same extent of the native GR heterocomplex (lane 2), but very little hsp90 is reassociated with the steroid-bound receptor (lane 6).

At this time, we are unable to determine whether the steroid-bound receptor is a poor substrate for the heterocomplex reconstitution system or whether it is not a

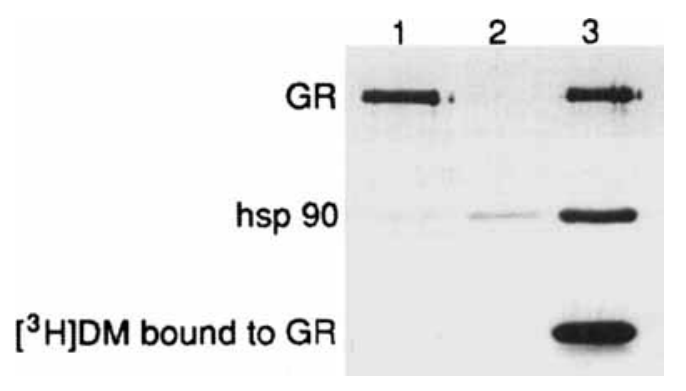

FIGURE 1. Reconstitution of the GR heterocomplex restores the receptor to the steroid binding conformation. Lane 1 shows GR that was immunoadsorbed from mouse L cell cytosol and salt-stripped of associated proteins. The stripped immunopellet (protein A-Sepharosebound GR-antibody complex) was divided into two portions with one portion being assayed for GR and hsp90 by Western blotting (top and middle panels, respectively) and the other portion being used for assay of steroid binding by incubating with the site-specific affinity ligand $\left[{ }^{3} \mathrm{H}\right]$ dexamethasone 21 -mesylate followed by gel electrophoresis and autoradiography. Lane 3 shows an identical sample that was stripped and then incubated with reticulocyte lysate to reassociate it with hsp90 and reactivate it to the steroid binding state. Lane 2 shows a nonimmune sample that was stripped and incubated with reticulocyte lysate in the same manner. 


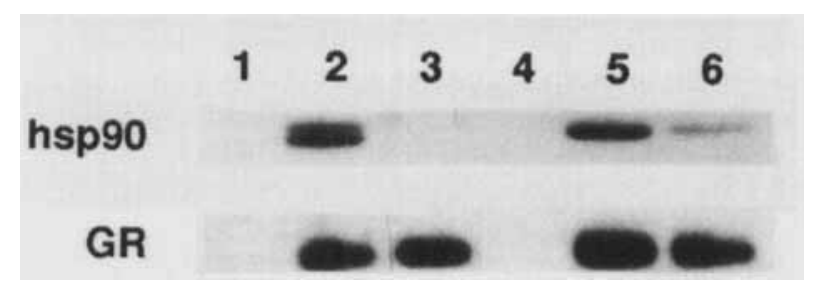

FIGURE 2. The hormone-free GR is reassociated with hsp90. Hormone-free or triamcinolone acetonide-bound receptors were immunoadsorbed to protein A-Sepharose, stripped of associated proteins and incubated with reticulocyte lysate. The figure shows an immunoblot of GR and hsp90 in immunopellets treated as follows: Lane 1, nonimmune; lane 2, immunoadsorbed hormone-free GR not stripped; lane 3, hormone-free GR stripped of associated proteins; lane 4, nonimmune sample that was stripped and incubated with reticulocyte lysate; lane 5, hormone-free GR stripped and incubated with lysate; lane 6, steroid-bound GR stripped and incubated with lysate.

substrate at all. We know that some steroid dissociates from the GR during the incubation with reticulocyte lysate, and it may be only this unbound fraction that is reassociated with hsp90, yielding the low level of reconstitution seen for the steroidbound sample in lane 6 .

In the experiment of Figure 3A, receptors in $\mathrm{L}$ cell cytosol were first incubated with $\mathrm{KCl}$ to dissociate them from hsp90, transforming them to the DNA-binding state. The receptors were then bound to DNA-cellulose. Replicate aliquots of DNAbound GR were then incubated with buffer or reticulocyte lysate, and both the receptor remaining bound to DNA and the receptor released from DNA were assayed by Western blotting. It can be seen that salt treatment caused the hormone-free GR to bind to DNA (cf. lanes 1 and 2) and that reticulocyte lysate caused the temperature-dependent release of the DNA-bound receptor (lanes 4 and 5). As shown in FIGURE 3B, hormone-free GR is readily released from DNA by lysate (lane 3 ) whereas very little hormone-bound receptor is released (lane 4). Again, we have determined that some steroid is released from the DNA-bound receptor during the $30{ }^{\circ} \mathrm{C}$ incubation with lysate so it could be just hormone-free GR that is released.

We performed the experiment of FIGURE 4 to determine the structural and functional state of the GR that was released from DNA. In this experiment, salt-transformed, hormone-free GR was bound to DNA-cellulose, the DNA-cellulose pellet was divided, and receptors were released from one portion by incubating at $30^{\circ} \mathrm{C}$ with $0.5 \mathrm{M} \mathrm{NaCl}$ and from the other portion by incubating at $30^{\circ} \mathrm{C}$ with reticulocyte lysate. In each case, a portion of the receptor released from DNA was immunoadsorbed for assay of GR-associated hsp90 and steroid binding activity, and another portion of released receptor was assayed for its ability to rebind to DNA-cellulose. It is clear that GR released from DNA with salt is not bound to hsp90, has no steroid binding activity, and is in the DNA-binding form. In contrast, GR released from DNA by reticulocyte lysate is now bound to hsp 90 , has high affinity steroid-binding activity, and does not have DNA-binding activity. Thus, the reticulocyte lysate has removed the GR from DNA and restored it to the non-DNA-binding state characteristic of the untransformed GR-hsp90 heterocomplex. This represents the first clear reversal of the process of steroid receptor transformation in a cell-free system. 


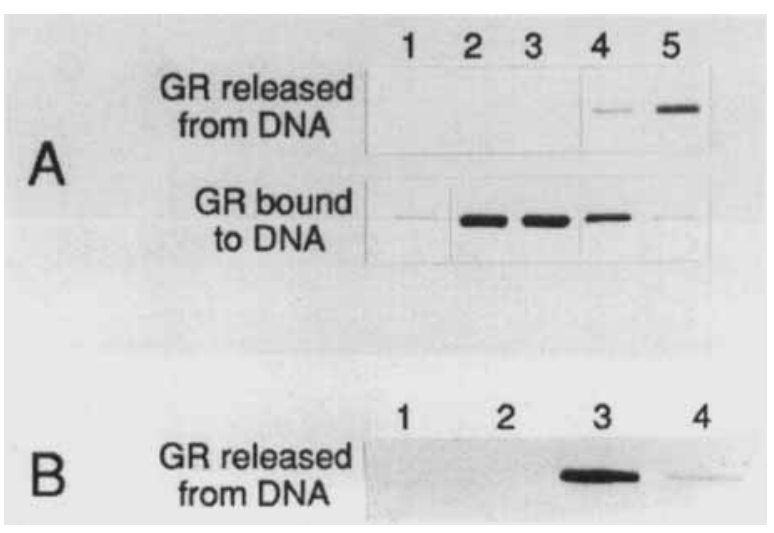

FIGURE 3. Reticulocyte lysate causes the release of GR from the DNA-receptor complex. Panel A. L cell cytosol containing hormone-free GR was treated with $0.4 \mathrm{M} \mathrm{KCl}$ and the transformed receptors were bound to DNA-cellulose. Aliquots of DNA-bound receptor were incubated with buffer or reticulocyte lysate for $20 \mathrm{~min}$ and both the GR remaining in the pellet and the GR released from DNA were assayed by Western blotting. Lane 1, receptor bound to DNA without salt treatment; lane 2, KCl-transformed receptor bound to DNA; lanes 3-5, DNA-bound GR incubated with HEPES buffer at $30^{\circ} \mathrm{C}$ (lane 3), reticulocyte lysate at $0{ }^{\circ} \mathrm{C}$ (lane 4), or reticulocyte lysate at $30^{\circ} \mathrm{C}$ (lane 5). Panel B. Effect of steroid on the ability of the receptor to be released from DNA. Receptors in one portion of $\mathrm{L}$ cell cytosol were bound with triamcinolone acetonide, and the other portion remained hormone-free. Then, both hormone-free and steroid-bound receptors were transformed with $\mathrm{KCl}$ and bound to DNAcellulose. The Western blot shows GR released from DNA when incubated under the following conditions for $10 \mathrm{~min}$ at $30^{\circ} \mathrm{C}$ : Lane 1 , hormone-free GR incubated with HEPES buffer; lane 2, hormone-free GR incubated with boiled reticulocyte lysate; lane 3 , hormonefree receptor released with normal lysate; lane 4, steroid-bound receptor released with normal lysate. All samples contained the same amounts of DNA-bound receptor prior to incubation with buffer or lysate. (Scherrer $e t$ al. ${ }^{38}$ Reproduced with permission of the American Society for Biochemistry and Molecular Biology).

\section{Conditions for Glucocorticoid Receptor Heterocomplex Formation}

Ultimately, we would like to purify the reconstitution system from reticulocyte lysate and define the mechanism of heterocomplex assembly. Reconstitution of both $\mathrm{PR}^{42}$ and $\mathrm{GR}^{41}$ heterocomplexes is an ATP-dependent process. The experiment of Figure 5 demonstrates that both ATP and small $\mathrm{M}_{\mathrm{r}}$ components of lysate are required for efficient GR heterocomplex assembly. In this experiment, GR that was stripped of associated proteins (lane 1) was incubated with lysate that had been dialyzed overnight (lane 4). It is clear that dialysis inactivated the ability of the lysate to assemble the GR heterocomplex and to reactivate steroid binding capacity (cf. lanes 3 and 4). Readdition of the small $M_{r}$ components of reticulocyate lysate in the form of a Centricon C30 filtrate of normal lysate back to dialyzed lysate did not regenerate heterocomplex assembly activity (lane 5). Addition of an ATP-generating system to dialyzed lysate had only a small effect, but addition of both ATP and the C30 filtrate (lane 7) restored the reconstituting activity to the level seen with normal lysate (lane 3). 


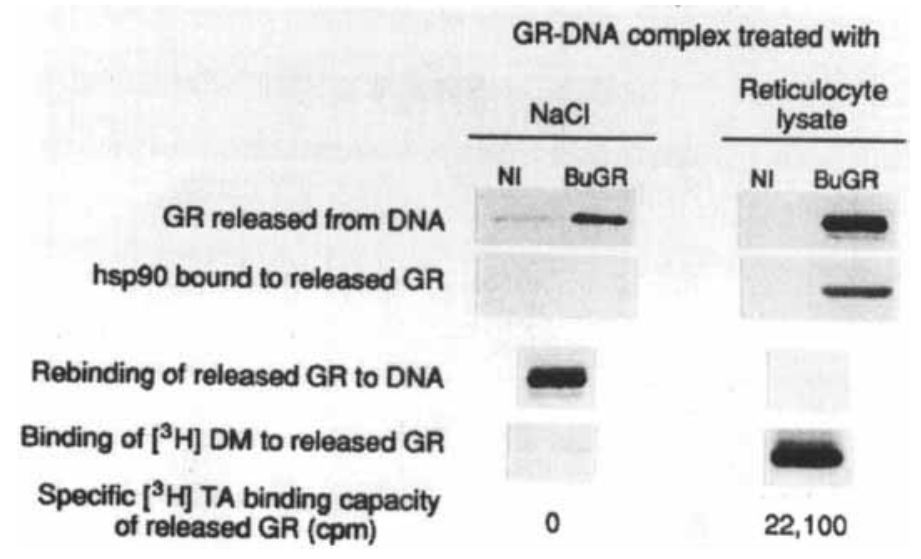

FIGURE 4. Receptor released from DNA by reticulocyte lysate is bound to hsp90 and is in the steroid-binding state. Receptors in hormone-free $\mathrm{L}$ cell cytosol were treated with $\mathrm{KCl}$ and bound to DNA-cellulose. The DNA-cellulose pellet was divided and receptors were released from one portion by incubating for $10 \mathrm{~min}$ at $30^{\circ} \mathrm{C}$ with buffer containing $0.5 \mathrm{M} \mathrm{NaCl}$; they were released from the other portion by incubating with reticulocyte lysate. A portion of the released receptor was immunoadsorbed with the BuGR monoclonal antibody, and part of the immunopellet was assayed for both GR and hsp 90 by Western blotting. The remainder of the immunopellet was divided, with one-half being incubated with $\left[{ }^{3} \mathrm{H}\right]$ dexamethasone 21 -mesylate followed by gel electrophoresis and autoradiography, and the other half being incubated with $\left[{ }^{3} \mathrm{H}\right]$ triamcinolone acetonide followed by washing of the immunopellet and scintillation counting. A second portion of the released receptor was diluted to reduce the salt concentration and then rebound to DNA-cellulose. (Scherrer et al. ${ }^{38}$ Reproduced with permission of the American Society for Biochemistry and Molecular Biology).

The active component of the Centricon C30 filtrate of lysate was shown to be heat-stable and to be replaced by potassium ion. ${ }^{41}$ The effect of monovalent cations on activation of GR steroid binding activity by dialyzed lysate in the presence of an ATP-generating system is shown in FIGURE 6. We have demonstrated a clear monovalent cation selectivity for lysate-mediated association of both hsp90 and hsp70 with the GR and activation of steroid binding capacity, with $\mathrm{K}^{+}, \mathrm{NH}_{4}^{+}$, and $\mathrm{Rb}^{+}$being active, $\mathrm{Cs}^{+}$having intermediate activity, and $\mathrm{Na}^{+}$and $\mathrm{Li}^{+}$being inactive. This cation specificity is typical of a weak nonvalent cation binding site. It is interesting that the protein unfoldase (e.g., clathrin uncoating ATPase) activity of hsp70 has a similar monovalent cation dependence. ${ }^{43,44}$

Having identified the small $M_{r}$ components required for heterocomplex reconstitution, we are now attempting to define the macromolecular components of the system. As part of this effort, we have shown that a heat shock protein complex $(200-250 \mathrm{kDa})$ partially purified from rabbit reticulocyte lysate by ammonium sulfate fractionation and Sepharose CL-6B chromatography could reconstitute a GR-hsp90 complex. ${ }^{45}$ This complex was originally purified for its ability to maintain a fusion protein bearing the mitochondrial matrix-targeting signal in a state that is competent for mitochondrial import-an hsp70-dependent function. ${ }^{46} \mathrm{We}$ showed that this partially purified complex contained hsp 70, hsp90, and hsp56. The partially purified protein complex had a very low capacity to reconstitute the GR heterocom- 


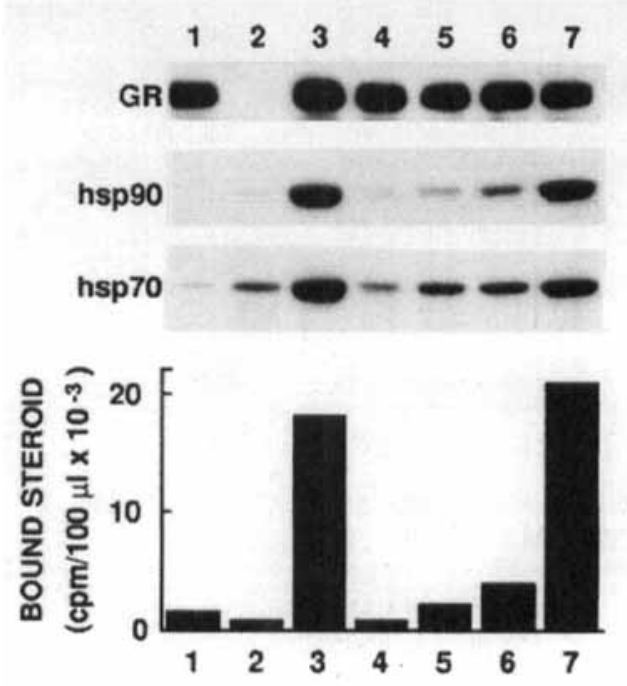

FIGURE 5. Small $\mathrm{M}_{\mathrm{r}}$ components of reticulocyte lysate are required for reconstitution of the GR-hsp90 complex. Immunoadsorbed receptors stripped of hsp90 were incubated with various combinations of reticulocyte lysate, dialyzed lysate, Centricon C30 filtrate of lysate, and an ATP-generating system for $25 \mathrm{~min}$ at $30^{\circ} \mathrm{C}$. The immune pellets were then assayed for steroid binding (bar graph) and for GR, hsp90, and hsp70 (immunoblots). Lane 1, immunoadsorbed GR pellet stripped of hsp90; lane 2, nonimmune pellet plus untreated lysate and ATP; lane 3, immune pellet plus untreated lysate and ATP; lane 4, immune pellet plus dialyzed lysate; lane 5, immune pellet plus dialyzed lysate and $\mathrm{C} 30$ filtrate; lane 6 , immune pellet plus dialyzed lysate and ATP; and lane 7, immune pellet plus dialyzed lysate, C30 and ATP.

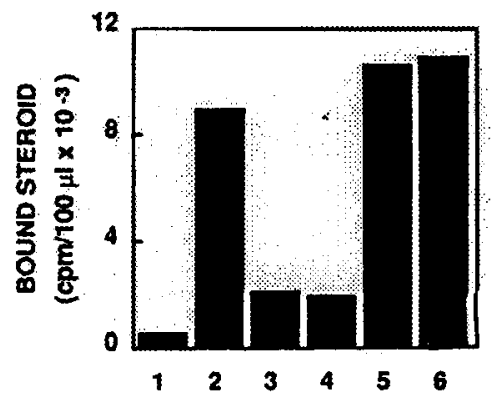

FIGURE 6. Monovalent cation selectivity for ATP-dependent activation of GR steroid binding capacity by dialyzed lysate. Immunoadsorbed receptors stripped of hsp90 were incubated for $20 \mathrm{~min}$ at $30^{\circ} \mathrm{C}$ with an ATP-regenerating system and untreated lysate, dialyzed lysate or dialyzed lysate with $50 \mathrm{mM} \mathrm{NaCl}, \mathrm{KCl}$, or $\mathrm{NH}_{4} \mathrm{Cl}$. Samples were then washed and assayed for steroid binding. Lane 1, stripped receptors; lane 2, stripped receptors plus untreated lysate; lane 3 , stripped receptors plus dialyzed lysate; lanes $4-6$, stripped receptors plus dialyzed lysate and $\mathrm{Na}^{+}$(lane 4); $\mathrm{K}^{+}$(lane 5); $\mathrm{NH}_{4}^{+}$(lane 6). 
plex compared to unfractionated reticulocyte lysate, but the GR that is rebound to hsp90 is converted to a steroid binding state in an ATP-dependent manner. ${ }^{45}$

Because the activity of the complex was very low, it was clear that some component (or components) of reticulocyte lysate is required for heterocomplex reconstitution besides ATP/ $\mathrm{Mg}^{2+}, \mathrm{K}^{+}$, hsp90, and possibly hsp70 and hsp56. We have found that the additional component (or components) required for efficient GR heterocomplex reconstitution is lost at the original ammonium sulfate step of the purification, and it is clearly present in the 50\% ammonium sulfate supernatant fraction that was discarded. ${ }^{45}$ It is already clear that purifying and defining this heterocomplex assembly system will be a difficult and long-term process.

\section{Assembly of Protein Kinase-hsp90 Heterocomplexes}

We wanted to determine if the reticulocyte lysate had a general ability to form other protein-hsp 90 heterocomplexes beyond its activity with steroid receptors. It has been known for many years that the $\mathrm{pp} 60^{\text {v-src }}$ transforming protein kinase encoded in Rous sarcoma virus is associated with hsp90 and a $50-\mathrm{kDa}$ protein of unknown function, p50. ${ }^{47,48}$ As soon as it is translated in the cell, pp60-src associates with these proteins and remains in the heterocomplex until it localizes to cell membranes (for review, see Brugge ${ }^{49}$ ). Thus, we asked if reticulocyte lysate would reconstitute the pp60 ${ }^{v-s r c}$-hsp90-p50 heterocomplex. ${ }^{39}$

In the experiment of FIGURE 7, PA104 mutant of pp60 $60^{\nu-s r c}$, which is normally present almost entirely as a soluble complex in association with hsp 90 and $\mathrm{p} 50,{ }^{50}$ was immunoadsorbed and salt-stripped of associated proteins. Both hsp 90 and p50 were coimmunoadsorbed in a manner that is immune-specific for the presence of $\mathrm{pp} 60^{\text {v-src }}$ (cf. lanes 1 and 2). When the stripped immunopellets were incubated with reticulocyte lysate, both hsp 90 and p50 were reassociated in a manner that was specific

FIGURE 7. Reticulocyte lysate reconstitutes the heterocomplex of PA104 pp60-src with hsp90 and p50. Aliquots of cytosol containing PA104 pp60 ${ }^{\nu-s r c}$ were immunoadsorbed to protein A-Sepharose with anti-pp60 $0^{\text {src }}$ or nonimmune antibody, washed three times with RIPA buffer, and then stripped of src-associated hsp 90 and p50 by incubation for $30 \mathrm{~min}$ at $45^{\circ} \mathrm{C}$ in RIPA buffer with $0.5 \mathrm{M} \mathrm{NaCl}$ followed by washing with low-salt buffer. Immune pellets were then incubated with reticulocyte lysate for $20 \mathrm{~min}$ at $30^{\circ} \mathrm{C}$, washed several times with buffer, and hsp 90 and p50 were detected by Western blotting. Lane 1, nonimmune, unstripped; lane 2, immune, unstripped; lane 3, nonimmune stripped; lane 4, immune stripped; lane 5 , nonimmune stripped incubated with lysate; lane 6 , immune stripped incubated with lysate. 
for the viral tyrosine kinase (cf. lanes 5 and 6 ), the presence of which was verified by Western blotting (data not shown).

Unlike the GR, there is no functional assay for determining whether the reconstituted pp60 ${ }^{\text {r-src }}$ heterocomplex is the same as the native complex, but some structural features suggest they are similar. Most notably, the thermal stabilities of the two complexes are similar, ${ }^{39}$ and both complexes are stabilized by molybdate and other transition metal oxyanions that stabilize steroid receptor heterocomplexes. ${ }^{39,51}$ Additionally, the reconstituted complex contains the p50 component of the native heterocomplex as well as hsp90.

Recently, we have broadened our search for proteins that can be assembled into an hsp90-containing heterocomplex by extending it to a protein that has never been found in native association with hsp90. The c-Raf-1 protein is a 74-kDa serine/threonine kinase implicated in normal mitogenic signal transduction and one that can be oncogenically activated by mutation..$^{52}$ We used a baculovirus system to express c-Raf-1 in Sf9 insect cells and immunoadsorbed the c-Raf-1 protein with a specific antiserum. This immunopellet was then incubated with reticulocyte lysate without prior stripping. As shown in lane 2 of FIGURE 8, the anti-Raf serum did not coimmunoadsorb any insect hsp90, which migrates slightly faster than rabbit hsp 90 . When the immunopellet containing the c-Raf-1 protein was incubated with reticulocyte lysate, rabbit hsp 90 was associated in a manner that was immune-specific for c-Raf-1 (cf. lanes 3 and 4), the presence of which was confirmed by additional Western blotting (data not shown). It will be of considerable interest to determine whether the association of c-Raf- 1 with hsp90 has affected its kinase activity.

\section{DISCUSSION}

Although the experiments we have presented here have focused on reticulocyte lysate-mediated association of proteins only with hsp 90 , it is important to realize that a multiprotein heterocomplex is being formed. For example, the lysate-reconstituted GR heterocomplex contains hsp70, ${ }^{41} \mathrm{hsp} 56,53$ and a $23-\mathrm{kDa}$ protein (P. R. Housley, personal communication) that has been reported as a component of native GR and PR heterocomplexes. ${ }^{15,16}$ The lysate-reconstituted PR heterocomplex contains hsp70 and $\mathrm{p} 23,42$ and the lysate-reconstituted $\mathrm{pp} 60^{\mathrm{v}-\mathrm{src}}$ heterocomplex contains hsp 70 and $\mathrm{p} 50,{ }^{39}$ in addition to hsp90.

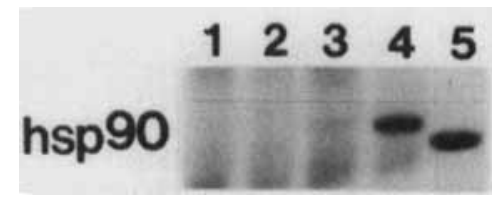

FIGURE 8. Reticulocyte lysate causes hsp90 to associate with the c-Raf-1 protein kinase. Lysates from infected Sf9 insect cells expressing c-Raf-1 were immunoadsorbed with anti-Raf serum or preimmune serum. Immunopellets were then incubated for $20 \mathrm{~min}$ at $30^{\circ} \mathrm{C}$ with rabbit reticulocyte lysate, and after washing of the pellets, hsp90 was detected by Western blotting. Lane 1, sample immunoadsorbed with preimmune serum; lane 2, immunoadsorbed with anti-Raf; lane 3, preimmune immunopellet incubated with reticulocyte lysate; lane 4, anti-Raf immunopellet incubated with reticulocyte lysate; lane 5, sample of Sf9 cell lysate. 
At this time, it is not established whether the heterocomplexes are being formed in lysate by a process of ordered addition of individual proteins or whether the receptors and pp60 ${ }^{\nu-s r c}$ are being attached to an already existing complex. As we mentioned earlier and as summarized in detail in a recent review, ${ }^{54}$ complexes containing hsp90, hsp70, hsp56, and other proteins exist in cytosols independent of the presence of receptors or viral protein kinases. The possibility exists that the GR HBD becomes attached to such a preexisting heat shock protein complex in reticulocyte lysate. Our recent demonstration ${ }^{45}$ that a heteroprotein complex partially purified from reticulocyte lysate permits (albeit very limited) reconstitution of a functional GR heterocomplex is also consistent with the possibility that the receptor becomes attached to a preformed complex.

It seems quite clear that heterocomplex assembly is an ATP-dependent enzymatic process, and hsp 70 is thought to have a protein unfoldase activity ${ }^{20}$ that could play a role in the assembly process. Several observations suggest a role for hsp70 in the binding of hsp90 to receptors. First, both the Toft lab and our group have noted that reticulocyte lysate-mediated association of hsp90 with the GR, ${ }^{41,45} \mathrm{PR}^{42}$ and pp66 ${ }^{- \text {src }} 39$ is always accompanied by association with hsp70. Second, the associations of both hsp90 and hsp70 are monovalent cation-selective events, ${ }^{41}$ and a similar requirement has previously been shown for hsp70-mediated clathrin unfolding. ${ }^{43}$ Third, Smith et al. ${ }^{42}$ have reported that pretreatment of reticulocyte lysate with a monoclonal antibody against hsp70 inhibits assembly of the PR-hsp90 complex.

Both of the published models ${ }^{42,55}$ of the heterocomplex assembly assume that hsp70 and hsp90 are preassociated and act together as a tandem unit. Hsp70 may be the component that recognizes the folded state of the hormone binding domain and facilitates an ATP-dependent and monovalent cation-selective unfolding process leading to an initial tight association of the receptor to the heterocomplex. The process has been modeled as a two-step event in which the second step is the stabilization of the HBD by the hsp 90 component of the heat shock protein complex. The assembly process is undoubtedly more complex, but this simple model involves testable proposals that serve as a start for further work to define the assembly mechanism.

Because work with fusion proteins has shown that the GR or ER HBD carries an inactivation function that inactivates proteins that are structurally quite distinct from "zinc finger" proteins, 9,10 models of conferrable hormone regulation must accommodate a range of regulated structures and activities. Two models based on a role for hsp90 in receptor folding satisfy this requirement. In the model of Picard et al., ${ }^{9}$ hsp90 bound to the HBD causes the fusion protein as a whole to assume an "unfolded" conformation that is reversed on hormone binding and transformation. In a second model called the "docking" model,, 22 hsp90 determines an unfolded conformation of only the HBD, and the protein is biologically inactive until it is released from the multiprotein structure by steroid-mediated reversal of the unfolded conformation, permitting transfer of the protein to its ultimate site of action.

In both of these models based on protein folding, regulation of protein function can be exerted in the nucleus, at the inside of the plasma membrane or elsewhere in the cell. Thus, we have a particular interest in the possibility that c-Raf-1 protein function could be regulated in a similar folding paradigm. One could envision, for example, that c-Raf-1 associates with hsp 90 while it undergoes its normal transport to the inside of the plasma membrane, much as pp60 $0^{\gamma-s r c}$ is thought to be transported through the cytoplasm in the heterocomplex form to the plasma membrane. In the case of c-Raf-1, dissociation from the hsp90 component of the heterocomplex would be mediated via phosphorylation (for example, by the PGDF receptor). Indeed, it is 
possible that the key phosphorylation site(s) is only available when c-Raf-1 is maintained in the unfolded state by hsp 90 .

The ubiquity, the abundance, and the conservation of hsp90 support a role in essential cellular processes common to many proteins, such as protein folding and trafficking. It would not be surprising if, during the course of evolution, proteins of different structures and actions took advantage of this common interaction with an abundant heat shock protein to bring their function under control by hormones, autocoids, growth factors, etc.

\section{SUMMARY}

Incubation of immunopurified, hormone-free mouse glucocorticoid receptors with rabbit reticulocyte lysate results in ATP-dependent and monovalent cationdependent assembly of the GR into a heterocomplex with hsp90, hsp70, and hsp56. Heterocomplex assembly is accompanied by conversion of the receptor from a form that does not bind steroid to a high affinity steroid-binding conformation. Reticulocyte lysate also promotes ATP-dependent dissociation of unliganded receptors from a prebound receptor-DNA complex. Receptor released from DNA has been reconstituted into the heat shock protein heterocomplex and converted to the nonDNA-binding state. The reticulocyte lysate also reconstitutes $\mathrm{pp} 60^{v-s r c}$ into a heterocomplex containing hsp90 and p50, both of which are components of the native heterocomplex form of the tyrosine kinase in cytoplasm. Although the c-Raf-1 serine/threonine kinase has never been found in native association with hsp90, it can be assembled into a heat shock protein heterocomplex by the ATP-dependent system in reticulocyte lysate.

\section{REFERENCES}

1. Pratt, W. B. 1987. J. Cell. Biochem. 29: 51-68.

2. Pratt, W. B. 1990. Mol. Cell. Endocrinol. 74: C69-C76.

3. Pratt, W. B., D. J. Jolly, D. V. Pratt, S. M. Hollenberg, V. Giguere, F. M. Cadepond, G. Schweizer-Groyer, M. G. Catelli, R. M. Evans \& E. E. Baulieu. 1988. J. Biol. Chem. 263: 267-273.

4. Dalman, F. C., L. C. Scherrer, L. P. Taylor, H. Akil \& W. B. Pratt. 1991. J. Biol. Chem. 266: 3482-3490.

5. Cadepond, F., G. Schweizer-Groyer,I. Segard-Maurel, N. Jibard, S. M. Hollenberg, V. Giguere, R. M. Evans \& E. E. Baulieu. 1991. J. Biol. Chem. 266: 5834-5841.

6. Schowalter, D. B., W. P. Sullivan, N. J. Maihle, A. D. W. Dobson, O. M. ConNEely,B. W. O'Malley \& D. O. TofT. 1991. J. Biol. Chem. 266: 21165-21173.

7. Godowski, P. J., S. Rusconi, R. Miesfeld \& K. R. Yamamoto. 1987. Nature 325: 365-368.

8. Hollenberg, S. M., V. Giguere, P. Segui \& R. M. Evans. 1987. Cell 49: 39-46.

9. Picard, D., S. J. Salser \& K. R. Yamamoto. 1987. Cell 54: 1073-1080.

10. Ellers, M., D. Picard, K. R. Yamamoto \& J. M. Bishop. 1989. Nature 340: 66-68.

11. Picard, D. \& K. R. Yamamoto. 1987. EMBO J. 6: 3333-3340.

12. Scherrer, L. C., D. Picard, E. Massa, J. M. Harmon, S. S. Simons, K. R. Yamamoto \& W. B. Pratt. Submitted.

13. TaI, P. K., Y. Maeda, K. Nakao, N. G. Wakim, J. L. Duhring \& L. E. Faber. 1986. Biochemistry 25: 5269-5275.

14. Kost, S. L., D. Smith, W. Sullivan, W. J. Welch \& D. O. Toft. 1989. Mol. Cell. Biol. 9: 3829-3838. 
15. Bresnick, E. H., F. C. Dalman \& W. B. Pratt, 1990. Biochemistry 29: 520-527.

16. SMith, D. F., L. E. Faber \& D. O. TofT. 1990. J. Biol Chem. 265: 3996-4003.

17. Sanchez, E. R., M. Hirst, L. C. Scherrer, H.-Y. Tangm. J. welch, J. M. Harmon, S. S. Simons, G. M. Ringold \& W. B. Pratt. 1990. J. Biol. Chem. 265: 20123-20130.

18. Sanchez, E. R., L. E. Faber, W. J. Henzel \& W. B. Pratt. 1990. Biochemistry 29: 5145-5152.

19. Perdew, G. H. \& M. L. Whitelaw. 1991. J. Biol. Chem. 266: 6708-6713.

20. Rothman, J. E. 1989. Cell 59: 591-601.

21. Yem, A. W., A. G. Tomasselli, R. L. Heinrikson, H. Zurcher-Neely, V. A. Ruff, R. A. Johnson \& M. R. Dejbel. 1992. J. Biol. Chem. 267: 2868-2871.

22. TaI, P. K., M. W. Albers, H. Chang, L. E. Faber \& S. L. Schreiber. 1992. Science 256: 1315-1318.

23. Walsh, C. T., L. D. Zydowsky \& F. D.McKeon. 1992. J. Biol. Chem. 267: 13115-13118.

24. Lebeau, M. C., N. Massol, J. Herrick, L. E. Faber, J. M. Renolr, C. Radanyi \& E. E. Baulieu. 1992. J. Biol. Chem. 267: 4281-4284.

25. Pratt, W. B. 1992. Bioessays 14: 841-848.

26. Dalman, F. C., R. J. Koenig, G. H. Perdew, E. Massa \& W. B. Pratt. 1990. J. Biol. Chem. 265: 3615-3618.

27. Dalman, F. C., L. J. Sturzenbecker, A. A. Levin, D. A. Lucas, G. H. Perdew, M. Petkovitch, P. Chambon, J. F. Grippo \& W. B. Pratt. 1991. Biochemistry 30: 5605-5608.

28. Bresnick, E. H., F. C. Dalman, E. R. Sanchez \& W. B. Pratt. 1989. J. Biol. Chem. 264: $4992-4997$.

29. Pongratz, I., G. G. F. Mason \& L. Poellinger. 1992. J. Biol. Chem. 267: 13728-13734.

30. Denis, M. \& J. A. Gustafsson. 1989. J. Biol. Chem. 264: 6005-6008.

31. Dalman, F. C., E. H. Bresnick, P. D. Patel, G. H. Perdew, S. J. Watson \& W. B. Pratt. 1989. J. Biol. Chem. 264: 19815-19821.

32. Schlatter, L. K., K. J. Howard, M. G. Parker \& C. W. Distelhorst. 1992. Mol. Endocrinol. 6: 132-140.

33. Smith, D. F., D. B. Schowalter, S. L. Kost \& D. O. Toft. 1990. Mol. Endocrinol. 4: 1704-1711.

34. Jove, R., B. J. Mayer, H. Iba, D. Laugier, F. Poirier, G. Calothy, T. Hanafusa \& H. HANAFUSA. 1986. J. Virol. 60: 840-848.

35. Gametchu, B. \& R. W. Harrison. 1984. Endocrinol. 114: 274-279.

36. Erhart, J. C., A. Duthu, S. Ullrich, E. Appella \& P. May. 1988. Oncogene 3: 595-603.

37. Whitelaw, M. L., K. Hutchison \& G. H. Perdew. 1991. J. Biol. Chem. 266: 1643616440.

38. Scherrer, L. C., F. C. Dalman, E. Massa, S. Meshinchi \& W. B. Pratt. 1990. J. Biol. Chem. 265: 21397-21400.

39. Hutchison, K. A., B. K. Brott, J. H. De Leon, G. H. Perdew, R. Jove \& W. B. Pratt. 1992. J. Biol. Chem. 267: 2902-2908.

40. Park, S., M. S. Marshall, J. B. Gibbs \& R. Jove. 1992. J. Biol. Chem. 267:11612-11618.

41. Hutchison, K. A., M. J. Czar, L. C. Scherrer \& W. B. Pratt. 1992. J. Biol. Chem. 267:14047-14053.

42. Smith, D. F., B. A. Stensgard, W. J. Welsh \& D. O. Toft. 1992. J. Biol. Chem. 267: $1350-1356$.

43. Schlossman, D. M., S. L. Schmid, W. A. Braell \& J. E. Rothman. 1984. J. Cell Biol. 99: 723-733.

44. Chappell, T. G., W. J. Welch, D. M. Schlossman, K. B. Palter, M. J. Schlesinger \& J. E. Rothman. 1986. Cell 45: 3-13.

45. Scherrer, L. C., K. A. Hutchison, E. R. Sanchez, S. K. Randall \& W. B. Pratt. 1992. Biochemistry 31: 7325-7329.

46. Sheffield, W. P., G. C. Shore \& S. K. Randall. 1990. J. Biol. Chem. 265: 11069-11076.

47. Brugge, J. S., E. Erikson \& R. L. Erikson. 1981. Cell 25: 363-372.

48. Courtneidge, S. A. \& J. M. Bishop. 1982. Proc. Natl. Acad. Sci. USA 79: 7117-7121.

49. Brugge, J. S. 1986. Curr. Top. Microbiol. Immunol. 123: 1-22.

50. Jove, R., E. A. Garber, H. Iba \& H. Hanafusa. 1986. J. Virol. 60: 849857. 
51. Hutchison, K. A., L. F. Stancato, R. Jove \& W. B. Pratt. 1992. J. Biol. Chem. 267: 13952-13957.

52. Li, P., K. Wood, H. Mamon, W. Haser \& T. Roberts. 1991. Cell 64: 479-482.

53. Hutchison, K. A., L. C. Scherrer, Y. Ning, E. R. Sanchez, K. L. Leach, M. R. Deibel \& W. B. Pratt. 1993. Biochemistry. In press.

54. Pratt, W. B. 1993. Role of heat shock proteins in steroid receptor function. In Steroid Hormone Action: Frontiers in Molecular Biology. M. G. Parker, Ed. Oxford University Press. Oxford. In press.

55. Pratt, W. B., L. C. Scherrer, K. A. Hutchison \& F. C. Dalman. 1992. J. Steroid Biochem. Molec. Biol. 41: 223-2292 